\title{
New Composite Membrane of Carboxylated Polysulfone (CPS)- Polyphenylene Ether Ether Sulfone (PPEES) as Potential Material for Direct Methanol Fuel Cell
}

\author{
C. Hegde ${ }^{1,2}$, A. M. Isloor ${ }^{3}$, G. Belavadi ${ }^{4} \&$ R. Kumar $^{5}$ \\ ${ }^{1}$ Department of Chemistry, Nitte Meenalsshi Institute of Technology, Yelahanka, Bangalore-64 India \\ ${ }^{2-5}$ Membrane Technology Division, Department of Chemistry, National Institute of Technology-Karnataka, \\ Surathkal, Mangalore 575 025, India
}

\begin{abstract}
In the present study, carboxylated polysulfone (CPS) and Poly (1,4-phenylene ether ether-sulfone) (PPEES) NF membranes for their application in proton exchange membrane fuel cells (PEMFCs) were investigated. New NF membranes were prepared by blending PPEES with CPS solution in NMP ( 5 wt. \%) by the solution casting procedure using $\mathrm{K}$-control coater. The membranes have been characterized by thermal analysis, water uptalse, IEC measurements, proton conductivity performance and methanol crossover. Electrochemical impedance spectroscopy (EIS) was at length used to decide proton conductivity. The addition of CPS increased the water uptake capability of the synthesized membrane and resulted in enhanced proton conductivity. The conductivity values in the range of $10^{-4}-10^{-2} \mathrm{~S} / \mathrm{cm}$ were obtained for the new CPS-PPEES membranes. The conductivities of the membranes showed increasing trend as a function of operating temperature and wt. \% of CPS. Membrane of the type CMI gave the conductivity in the range of $0.12 \mathrm{~S} / \mathrm{cm}$ at $100^{\circ} \mathrm{C}$. The results showed that, CPS/PPEES is a promising membrane material for possible use in proton exchange membrane fuel cells.
\end{abstract}

Keywords: Carboxylated polysulfone, proton conductivity, methanol crossover, fuel cell

\subsection{INTRODUCTION}

A fuel cell is an electrochemical device that converts the chemical energy of fuels directly into electrical energy to provide a clean and highly efficient source of electrical energy. The six basic types of fuel cell are classified by the electrolyte that they employ. Low temperature types include the allkaline fuel cell (AFC), direct methanol fuel cell (DMFC) and proton exchange membrane fuel cell (PEMFC). The three high temperature types are the phosphoric acid fuel cell (PAFC), molten carbonate fuel cell (MCFC) and solid oxide fuel

\footnotetext{
"Corresponding to: A, M. Isloor (email; isloor@yahoo.com)
}

cell (SOFC) [1]. It is proved that, various types of membranes can be effectively used as proton exchange membranes in fuel cell technology because of its simplicity, viability, pollution free operation and quick start up [2]. The most commonly used proton exchange membrane is Nafion, which possess inherent chemical, thermal stability, oxidative stability and high proton conductivity [3]. High temperature application of a proton exchange membrane fuel cell (PEMFC) can be obtained from polymers with high glass transition temperatures such as polybenzimidazole [4].

Different types of membranes have been tested for use in PEM fuel cells. The membranes are 
usually, polymers modified to include ions, such as sulfonic groups, carboxylic groups etc. These hydrophilic ionic moieties are the key for allowing proton transport across the membrane. The favored polymer structure has changed to improve membrane lifetime and slow down membrane degradation [5]. As Nafion has limited operation at temperatures up to $80^{\circ} \mathrm{C}$, since it functions only under highly hydrated state. So different approaches have been studied by research groups for the development of alternate membranes for PEM fuel cells. Sulfonated polyethersulphone (PES) or polyetheretherketone (SPEEK) [6], sulfonated polysulfone / titanium dioxide composite membranes [7] and phosphoric acid doped polybenzimidazole membranes [8] are the new focuses of the field.

Present study describes preparation of polysulfone and modified polysulfone composite membranes. Newly prepared were membranes further characterized for its water uptake, swelling and ion exchange capacity. Increased hydrophilicity of the CPS-PPEES membranes resulted in increase of swelling rate and also in proton conductivity value. Moreover its reduced methanol crossover value makes it suitable material for PEMFC.

\subsection{EXPERIMENTAL}

\subsection{Materials and Method}

Polysulfone (PS) having molecular weight of 35,000, Poly (1,4-phenylene ether ether-sulfone), (PPEES) were obtained from Sigma Aldrich in the form of semitransparent beads. Required CPS was synthesized as per the procedure reported in the literature [9-11]. Reagent grade N-methyl pyrrolidone, NMP was obtained from MerckIndia and was used without any further purification. All analytical grade chemical reagents used in the experiment were purchased from Merck India Ltd. For casting the membranes, KControl coater purchased from UK was used. IR spectra were recorded using Nicolet Avatar 5700 FTIR (Thermo Corporation) spectrometer. Impedance study was done using AUTOLAB PGSTAT30 Instrument. SEM images of the cross section of the newly prepared membranes were made with a Joel JSM-84. DSC study was carried out on a Shimadzu DSC 60 instrument, Japan.

Prepared membranes were studied for water uptake, swelling and ion exchange capacity experiments. To find the application for direct methanol fuel cells these synthesized membranes were subjected to proton conductivity and methanol crossover experiments.

\subsection{Synthesis of PS-PPEES NF Membrane}

Solutions containing different wt. \% of PS and PPEES (Table 1) in $4.5 \mathrm{~mL}$ of 1-methyl-2. pyrrolidone (NMP) were prepared. The solution was stirred for 24 hours at $75^{\circ} \mathrm{C}$ for completion of dissolution. Further stirring was stopped for 30 minutes and obtained viscous solution was casted using K-Control coater. Casted membrane was again heat-treated for 45 seconds at $220^{\circ} \mathrm{C}$. The membranes were separated by dipping the glass plates in distilled water. Further separated membranes were dipped in distilled water for another 24 hours; these membranes were washed several times with distilled water before storage [12].

Table 1 Solutions containing different wt.\% of PS and PPEES

\begin{tabular}{lll}
\hline $\begin{array}{l}\text { Membrane } \\
\text { Code }\end{array}$ & $\begin{array}{l}\text { Wt.\% composition } \\
\text { (PS) }\end{array}$ & $\begin{array}{l}\text { Wt.\% composition } \\
\text { (PPEES) }\end{array}$ \\
\hline M1 & 90 & 10 \\
M2 & 80 & 20 \\
M3 & 70 & 30 \\
M4 & 60 & 40 \\
\hline
\end{tabular}

\subsection{Synthesis of Carboxylated Polysulfone (CPS)-PPEES NF Membrane}

Solutions containing different wt. \% of CPS and PPEES (Table 2) in $4.5 \mathrm{~mL}$ of 1-methyl-2pyrrolidone (NMP) were prepared by mild stíring for one day at constant temperature of $75^{\circ} \mathrm{C}$. Obtained viscous solution was casted over glass plate using K-Control coater. Casted membrane 
was again heat-treated for 45 seconds at $220^{\circ} \mathrm{C}$, then washed thoroughly with deionized water and immersed in de-ionized water for $24 \mathrm{~h}$. Figure 1 shows the schematic route for the synthesis of CPS- PPEES membranes [12].

Table 2 Solutions containing different wt.\% of CPS and PPEES

\begin{tabular}{lll}
\hline $\begin{array}{l}\text { Membrane } \\
\text { Code }\end{array}$ & $\begin{array}{l}\text { Wt.\% composition } \\
\text { (CPS) }\end{array}$ & $\begin{array}{l}\text { Wt.\% composition } \\
\text { (PPEES) }\end{array}$ \\
\hline CM1 & 90 & 10 \\
CM2 & 80 & 20 \\
CM3 & 70 & 30 \\
CM4 & 60 & 40 \\
\hline
\end{tabular}

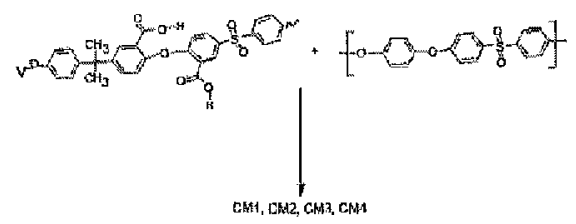

Figure 1 Schematic route for the synthesis of CPS-PPEES membranes

\subsection{Structural Characterization}

IR spectra were recorded using Nicolet Avatar 5700 FTIR (Thermo Corporation) spectrometer. Differential scanning calorimetric analysis (DSC) was performed on a Shimadzu $60 \mathrm{DSC}$ instrument at a heating rate of $10^{\circ} \mathrm{C}$ in liquid nitrogen. Scanning electron microscope (Jeol JSM-84) was used to observe the microstructures of the dried membranes.

\subsection{Water Uptake Studies}

The water uptake of the synthesized membrane was determined by measuring the change in the weight after the hydration. The membrane was first immersed in deionized water for $2 \mathrm{hr}$. Then the membrane was weighed quickly after removing the water present on the surface to determine the weight of wet membrane $\left(W_{\text {wet }}\right)$.
The weight of the dry membrane $\left(W_{d r y}\right)$ was determined after drying. The percentage of water uptake was calculated by using the following equation [13]:

$$
\text { Water uptake }(\%)=\frac{W_{w e t}-W_{d r y}}{W_{d r y}} \times 100
$$

\subsection{SwellingStudies}

The surface swelling characteristics were determined by measuring the change of the membrane geometrical area upon equilibrating the membranes in water at room temperature for 2 hrs. The swelling ratio was calculated by the following equation [13].

$$
\text { Swelling }(\%)=\frac{A_{w e t}-A_{d r y}}{A_{d r y}} \times 100
$$

where, $A_{d r y}$ and $A_{\text {wet }}$ are the area of dry and wet samples, respectively.

\subsection{Ion-exchange Capacity (IEC)}

The ion exchange capacity of the membranes was determined through an acid-base titration. The dry composite membrane was immersed in $50 \mathrm{~mL}$ of $1 \mathrm{M}$ sodium chloride aqueous solution for $24 \mathrm{~h}$ in order to extract all protons from the membrane. After taking out the membrane, electrolyte solution was titrated with $5 \mathrm{mM}$ sodium hydroxide solution using phenolphthalein as an indicator. The ion exchange capacity (IEC) was calculated using the following equation:

$$
\mathrm{IEC}=\frac{V X M}{W_{d r y}}
$$

where IEC is the ion exchange capacity (m equiv. $\mathrm{g}-1), V$ the added titrant volume at the equivalent point (ml), $M$, the molar concentration of the titrant and $W_{d r y}$ is the dry mass of the membranes [14].

\subsection{Proton Conductivity Study}

For proton conductivity measurement at different temperature, a polished and gold plated clean copper plate was pressed on both surfaces of the 
membranes to ensure good electrical contact. A nayquist impedance spectrum was recorded from $0.01 \mathrm{~Hz}$ to $1 \mathrm{MHz}$ using AUTOLAB PGSTAT30 instrument. The proton conductivity was calculated from the following Equation:

$$
\sigma(S / \mathrm{cm})=(t / A \times R m)
$$

where, $t$ is the thickness of the membrane sample $(\mathrm{cm}), R_{m}$ is the area resistance of the membrane $\left(\Omega \mathrm{cm}^{2}\right)$ and $A$ is the area of the electrode $\left(\mathrm{cm}^{2}\right)$ [15].

\subsection{Methanol Crossover}

Cyclic voltammetric system was used to estimate the amount of crossed over methanol. In this experiment, a two glass cell compartment separated by the membrane was used. Before starting the measurements, membranes were immersed in deionised water for $24 \mathrm{~h}$ to attain hydration equilibrium. Platinum foil with a geometric surface area of $2 \mathrm{~cm}^{2}$ and smooth platinum electrode were used as working and counter electrode, and $\mathrm{Ag} / \mathrm{AgCl}$ (saturated $\mathrm{KCl}$ ) electrode as the reference. The working electrode was immersed in one compartment considered as cathode and counter and reference electrode was immersed in the second compartment considered as anode. The cell was connected to BAS Epsilon potentiostat. A blank electrolyte of $50 \mathrm{ml}$ of $0.5 \mathrm{M}$ $\mathrm{H}_{2} \mathrm{SO}_{4}$ was first taken in either compartment of the cell and $\mathrm{C}-\mathrm{V}$ scanning was performed prior to the permeability test. The permeability was studied by introducing methanol of known concentration in $0.5 \mathrm{M} \mathrm{H}_{2} \mathrm{SO}_{4}$ to one compartment of the cell and analyzing the other compartment for its permeability. The permeability test was performed at room temperature for $1 \mathrm{M}$ initial methanol concentration at the anode compartment and cyclic voltammograms was recorded between 0.2 and $1 \mathrm{~V}$ and from the response the concentration of methanol in the cathode side was determined. The concentration of crossed methanol was determined from the calibration curve $[16,17]$.

\subsection{RESULTS AND DISCUSSIONS}

\subsection{Spectral Characterization}

Formation of the CPS- PPEES and PS-PPEES membrane was confirmed by IR spectroscopy. Figure 2 shows IR spectrum of the CPS- PPEES membrane. Figure 3 shows IR spectrum of the PS- PPEES membrane. From the Figure 3, following stretching frequencies were observed, $3600-3200 \mathrm{~cm}^{-1}$ for $\mathrm{O}-\mathrm{H}$ stretching vibrations, $2980-2880 \mathrm{~cm}^{-1}$ for asymmetric and symmetric $\mathrm{C}-\mathrm{H}$ stretching vibrations involving entire methyl group, $1412 \mathrm{~cm}^{-1}$ for asymmetric $\mathrm{C}-\mathrm{H}$ bending deformation of methyl group, $1365 \mathrm{~cm}^{-1}$ for symmetric $\mathrm{C}-\mathrm{H}$ bending deformation of methyl group, $1325-1298 \mathrm{~cm}^{-1}$ for doublet resulting from asymmetric $\mathrm{O}=\mathrm{S}=\mathrm{O}$ stretching of sulfone group, $244 \mathrm{~cm}^{-1}$ for symmetric C-O-C stretching of aryl ether group, $1170 \mathrm{~cm}^{-1}$ for asymmetric $\mathrm{O}=\mathrm{S}=\mathrm{O}$ stretching of sulfonate, $1150 \mathrm{~cm}^{-1}$ for symmetric $\mathrm{O}=\mathrm{S}=\mathrm{O}$ stretching of sulfone group, $1107-1092$

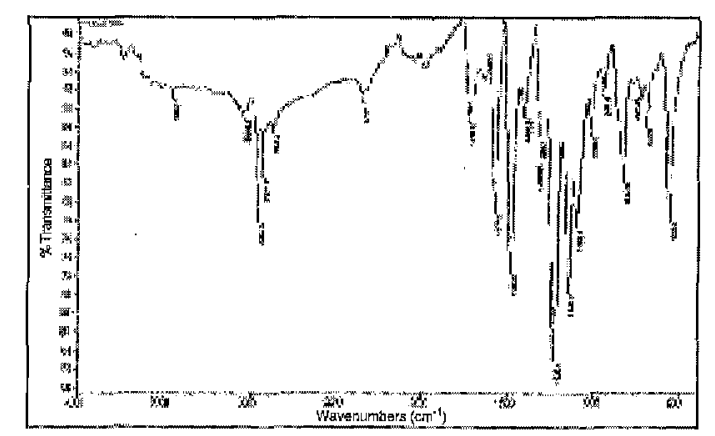

Figure 2 IR spectrum of the CPS-PPEES membrane

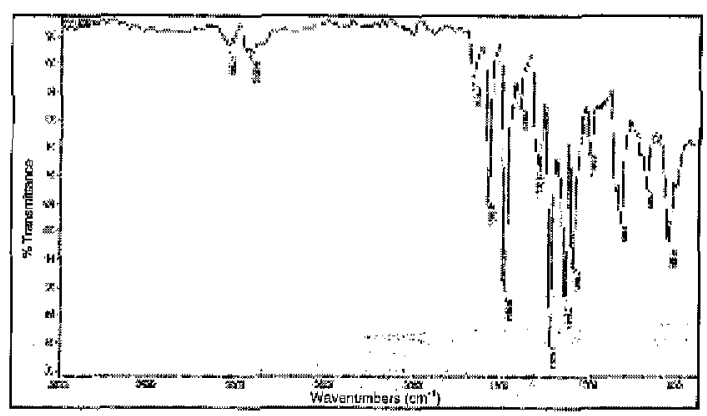

Figure 3 IR spectrum of the PS-PPEES membrane 
$\mathrm{cm}^{-1}$ for aromatic ring vibrations, $1027 \mathrm{~cm}^{-1}$ for symmetric $\mathrm{O}=\mathrm{S}=\mathrm{O}$ stretching of sulfonate group. From the Figure 2, for the membrane, CPSPPEES, gives following stretching frequencies were observed; carboxyl group was identified in $1577-1731 \mathrm{~cm}^{-1}, 3600-3200 \mathrm{~cm}^{-1}$ for $\mathrm{O}-\mathrm{H}$ stretching vibrations [9] along with above mentioned group frequencies.

\subsection{Water Uptake, Swelling and Ion Exchange Capacity (IEC)}

The water uptake, swelling and ion exchange capacity (IEC) play important roles in membrane conductivity. The water uptake of the CPS-PPEES membranes increases with increase of carboxylation concentration. This is due to the fact that the carboxylate groups are hydrophilic and hence the membranes with higher carboxylation can absorb more water [18]. From Table 3 and Table 5 , it was observed that the proton conductivity of the synthesized CPS-PPEES, NF membranes increases with increased wt. \% of carboxylated polysulfone. Proton transfer is enhanced by increasing the number of carboxylation. Proton conductivity of the membrane increases with increase of temperature. From the data, some increasing trend in swelling can be observed as the content of carboxylated polysulfone (CPS).

Carboxylated polysulfone (CPS) appears as hydrophilic materials compared with unmodified polysulfone. Titrations were conducted to quantitatively determine the experimental IECs. From the table it was observed that value of IEC increases with increase in water uptake and amount of CPS. These effects can be correlated to the increased hydrophilicity behaviour of the polysulfone polymer as more $-\mathrm{COOH}$ group facilitates more hydrogen proton conduction through the membrane matrix. From the Table 3, it is observed that membrane containing high wt $\%$ of CPS showed increase in the water uptake, swelling and IEC values. More interestingly, membrane CMI showed IEC value which is approximately equal to the IEC value of the nafion

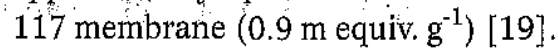

Table 3 Water uptake, swelling and IEC values for different membranes

\begin{tabular}{llll}
\hline $\begin{array}{l}\text { Membrane } \\
\text { Code }\end{array}$ & $\begin{array}{l}\text { Water } \\
\text { uptake } \\
(\%)\end{array}$ & $\begin{array}{l}\text { Swelling } \\
(\%)\end{array}$ & $\begin{array}{l}\text { IEC } \\
\text { (m equiv.g }{ }^{-1} \text { ) }\end{array}$ \\
\hline CM1 & 92 & 32 & 0.86 \\
CM2 & 75 & 15 & 0.72 \\
CM3 & 65 & 12 & 0.41 \\
CM4 & 45 & 07 & 0.15 \\
M1 & 08 & 03 & - \\
M2 & 17 & 16 & - \\
M3 & 22 & 19 & - \\
M4 & 35 & 24 & - \\
\hline
\end{tabular}

\subsection{Morphology of the Membranes}

The morphology of the membranes of the polysulfone and carboxylated polysulfone/PPEES membranes were studied by scanning electron microscopy (SEM). As illustrated in Figure 4, Figure 5, Figure 6, and Figure 7, the SEM pictures showed similar dense structure for the surface area of the CPS and normal polysulfone membranes. Figure 6 and Figure 7 shows surface image of the normal polysulfone and CPS with PPEES membranes respectively. From the Figure 6 , it was observed that noncarboxylated polysulfone -PPEES membrane show larger visible pores than CPS -PPEES membrane (Figure 7). It is assumed that this might be due to the presence of aggregates of carboxylic groups at the membrane surface. Figure 4 and Figure 5 shows cross section image of the CPS and normal polysulfone -PPEES membranes respectively. Cross section image of the membranes shows dense and channel-like microvoids which eases the flow of proton migration within the membrane matrix. It can be concluded that SEM study of the membranes however does not clearly signify the effects of carboxylation on the membrane structure. 


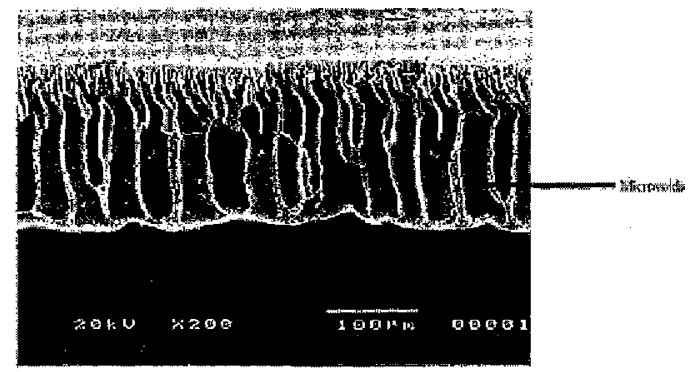

Figure 4 Cross section image of the CM1 membrane

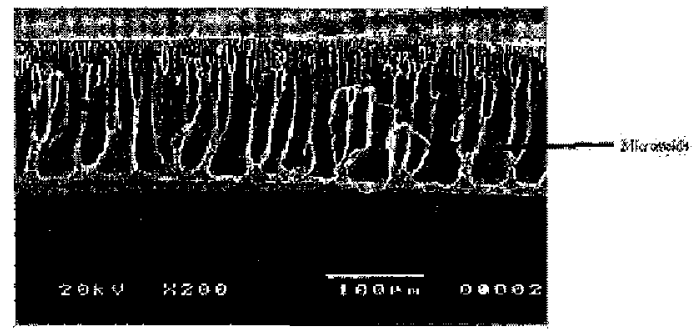

Figture 5 Cross section image of the M1 membrane membrane

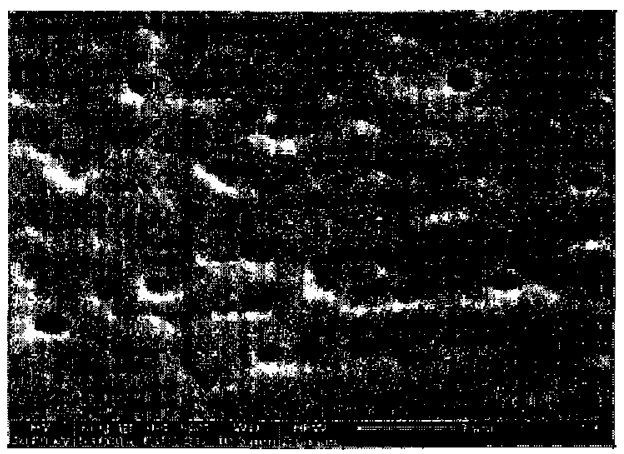

Figure 6 Surface image of the M1 membrane

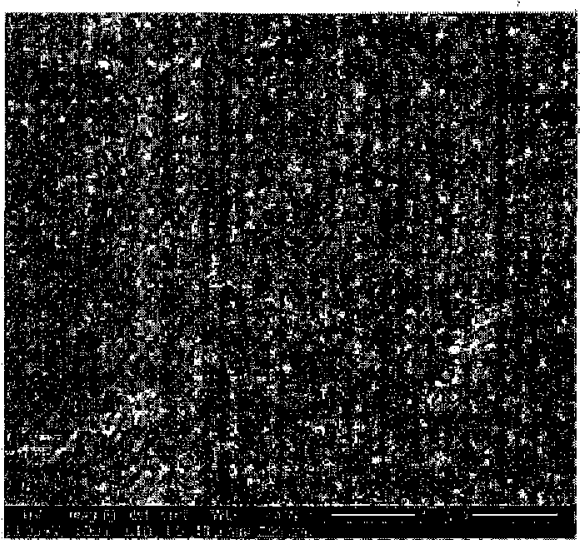

Figure 7 Surface image of the CM1 membrane

\subsection{Thermal Stability}

The glass transition temperature ( $\mathrm{Tg}$ ) of the synthesized membranes was measured by Differential Scanning Calorimetry (DSC) at the rate of heating $10^{\circ} \mathrm{C} / \mathrm{min}$ and values were presented in Table 4. The glass transition temperature of the membranes was detected in the range of $160^{\circ} \mathrm{C}$ and $300^{\circ} \mathrm{C}$. It was observed that, CPS-PPEES membranes showed higher Tg values than normal polysulfone-PPEES membranes. This inclination may be due to the following fact; firstly carboxylate group may decrease the free volume of the polymer chain, secondly due to the decreased molecular interaction by the pendant ion, thirdly increased molecular bulkiness on carboxylation. Figure 8 illustrates DSC thermogram for different membranes.

Table $4 \mathrm{Tg}$ of the different membranes

\begin{tabular}{ll}
\hline $\begin{array}{l}\text { Membrane } \\
\text { Code }\end{array}$ & I'g $\left({ }^{0} \mathrm{C}\right)$ \\
\hline CM1 & \\
CM2 & 235 \\
CM3 & 216 \\
M4 & 201 \\
M1 & 187 \\
M2 & 198 \\
M3 & 185 \\
M4 & 172 \\
\end{tabular}

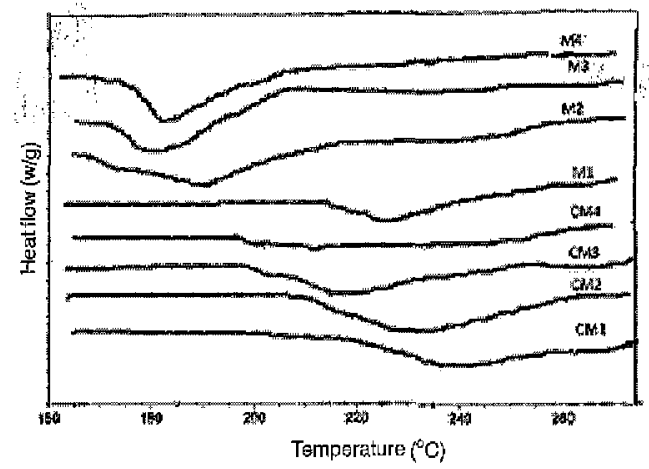

Figure 8 DSC thermogram for different membranes 
Table 5 Proton conductivity with temperature for M1, M2, M3 and M4-PPEES membranes

\begin{tabular}{llccc}
\hline $\begin{array}{l}\text { Membrane } \\
\text { Code }\end{array}$ & \multicolumn{3}{c}{ Temperature $\left({ }^{\circ} \mathrm{C}\right)$ and proton conductivity (S/cm) } \\
\hline M1 & 20 & 40 & 60 & 80 \\
\hline M2 & $1.8 \times 10^{-5}$ & $1.6 \times 10^{-4}$ & $1.9 \times 10^{-4}$ & $1.7 \times 10^{-3}$ \\
M3 & $2.2 \times 10^{-5}$ & $1.7 \times 10^{-4}$ & $1.1 \times 10^{-3}$ & $3.2 \times 10^{-3}$ \\
M4 & $6.0 \times 10^{-4}$ & $5.0 \times 10^{-4}$ & $3.2 \times 10^{-3}$ & $1.8 \times 10^{-3}$ \\
\hline
\end{tabular}

Table 6 Proton conductivity with temperature for CM1, CM2, CM3 and M4-PPEES membranes

\begin{tabular}{llccc}
\hline $\begin{array}{l}\text { Membrane } \\
\text { Code }\end{array}$ & \multicolumn{4}{c}{ Temperature $\left({ }^{\circ} \mathrm{C}\right.$ ) and proton conductivity (S/cm) } \\
\hline CM1 & 20 & 40 & 60 & 80 \\
\hline CM2 & 0.03 & 0.035 & 0.045 & 0.12 \\
CM3 & 0.02 & 0.029 & 0.038 & 0.072 \\
CM4 & 0.0026 & 0.0039 & 0.004 & 0.03 \\
\hline
\end{tabular}

\subsection{Proton Conductivity}

Electrochemical impendance spectroscopy was employed to determine the conductivity of the membranes. Obtained results from the proton conductivity measurementwere tabulated in Table 5 and Table 6 . It was observed from the study that, the membrane conductivity increased significantly with the increase in the CPS concentration. It is probably due to greater content of -COOH groups in the polymer chain, which enhances the facilitation of the proton transport within the membrane matrix . At higher temperature, water content in the membranes aggressively start facilitating proton transport resulting in higher proton conductivity. Though, the conductivity values of CPS-PPEES, which are in the range of $0.0016-0.12 \mathrm{~S} / \mathrm{cm}$, are still moderately lower than that of standard Nafion 117 membrane.

From the Table 5 and Table 6 , it is understood that, CPS-PPEES membranes showed increased proton conductivity than normal polysulfonePPEES membranes. Hence we compared former membranes conductivity with nafion 117 . Membrane CM1 gave increased proton conductivity than Nafion 117 at $100^{\circ} \mathrm{C}$ as mentioned in Figure 10, whereas Figure 9, illustrates nayquist spectrum of the membrane $\mathrm{CM} 1$ at different temperature.

\subsection{Methanol Crossover}

A key obstacle to high performance in direct methanol fuel cells (DMFC) is the mass transfer or "crossover" of methanol through the proton 
exchange membrane from the anode to cathode. Here we have used three membranes namely, $\mathrm{CM} 1$, CM2 and CM3 for the study of methanol crossover. Their performance was compared with nafion 117 membrane and results are presented in Figure 11. It was observed that, nafion 117 shows constant increase in methanol crossover with time. Comparatively CMI exhibited remarkable less methanol crossover than nafion 117 . This reduced methanol crossover of the CM1, CM2 and CM3 membranes, which is due to its hydrophilic nature which significantly increases retention of the methanol. Where as, relatively high hydrophobic nafion 117 eases high methanol crossover.This study undoubtedly indicates that, synthesized CPS-PPEES membranes reveal reduced methanol crossover [20].

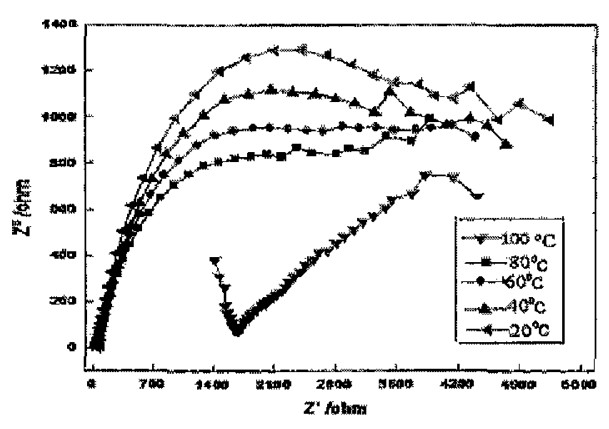

Figure 9 Nayquist impedance spectrum of the CM1 membrane

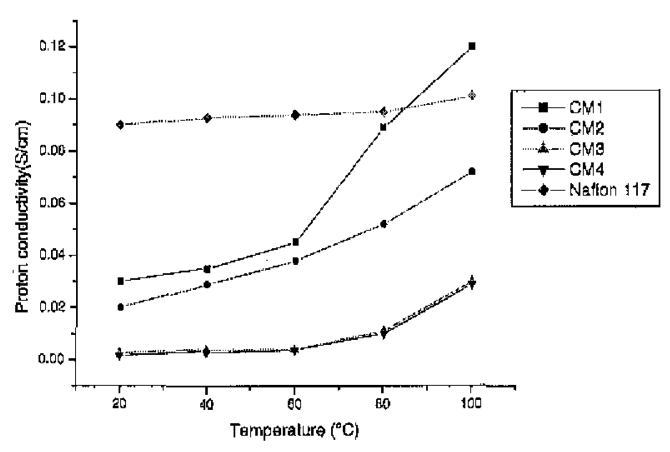

Figure 10 Comparison of proton conductivity of the synthesised membranes with Nafion 117

\subsection{CONCLUSIONS}

Present study includes synthesis of CPS and their composite membranes with PPEES. Prepared membranes were characterized in terms of water uptake, swelling, ion exchange capacity, proton conductivity and methanol crossover. Proton conductivity and methanol crossover measurements reveal that, CPS membranes have increased proton conductivity and decreased methanol crossover. Newly synthesized membranes exhibits reduced methanol crossover as compared to nafion 117 . Despite the fact that, these synthesized CPS-PPEES membranes shows lesser proton conductivity, its lower methanol crossover makes it as a potential membrane material in PEMFC.

\section{ACKNOWLEDGEMENT}

AMI thank Department of Atomic Energy, Board for Research in Nuclear Sciences, Government of India for 'Young Scientist' award. CH thanks Director, NMIT, Bangalore, India for providing research facility. RK thank Defense Research and Development (DRDO), New Delhi, India for the financial support.

\section{REFERENCES}

[1] Mathew, M. 2008. Fuel Cell Engines. John Wiley \& Sons Inc. Hoboken New Jersey.

[2] Barbir, F. 2005, PEM Fuel Cells: Theory and Practice. Elsevier Academic Press.

[3] Zaidi, J, and T. Matsuura. 2009. Polymer Membranes for Fuel Cells. Springer.

[4] Jannasch, P. 2003. Recent Developments in High-temperature Proton Conducting Polymer Electrolyte Membranes. Current Opinion in Colloid and Interface Science. 8: 96-102.

[5] Yoon, C. B., W. H. Meyer, and G. Wegner. 2001. New Functionalized Polyurethane with Proton Conductivity. Synthetic Met. 119: 465-66.

[6] Lei Li, and YuxinWang. 2005. Sulfonated Polyethersulfone Cardo Membranes for 
Direct Methanol Fuel Cell. J. Membrane Sci. 246: 167-172.

[7] Devrim, Y., S. Erkan., N. Baç, and I. Eroglu. 2009. Preparation and Characterization of Sulfonated Polysulfone/titanium Dioxide Composite Membranes for Proton. Exchange

Membrane Fuel Cells. International J. Hydrogen Energy. 34: 3467-3475.

[8] Li , Ming-Qiang, Shao, Zhi-Gang, and Scott Keith. 2008. A High conductivity $\mathrm{Cs}_{2.5}$ $\mathrm{H}_{0.5} \mathrm{PMo}_{12} \mathrm{O}_{40} /$ polybenzimidazole (PBI) $/ \mathrm{H}_{3} \mathrm{PO}_{4}$ composite membrane for protonexchange membrane fuel cells operating at high temperature. J.Power Sources .83: 6975.

[9] Yoshikawa, M., K. Tsubouchi., M. D. Guiver, and G. P. Robertson.1999. Modified polysulfone membranes. III. Pervaporation separation of benzene-cyclohexane mixtures rough carboxylated polysulfone membranes J. Appl. Polym. Sci. 74: 407-412.

[10] Guiver, M. D., S. Croteau., J. D. Hazlett, and 0 . Kutowy. 1999. Synthesis and Characterization of Carboxylated Polysulfones. Br. Polym. J. 23: 29-39.

[11] Sajitha, C.J., R. Mahendran, and D.Mohan.2002. Studies on cellulose acetate ${ }^{-c a r b o x y l a t e d ~ p o l y s u l f o n e ~ b l e n d ~}$ ultrafiltration membranes-Part I. European Polym. J. 38: 2507-2511.

[12] Chitrakara, H., M.A.Isloor., P. Mahesh.,W. Pikul, and L.Yu. 2011. Synthesis and desalination performance of $\mathrm{Ar}+-\mathrm{N}+$ irradiated polysulfone based new NF membrane. Desalination. 265:153- 158.

[13] Helen, M., B. Viswanathan, and S. Srinivasa
Murthy. 2007. Synthesis and characterization of composite membranes based on -zirconium phosphate and silicotungstic acid. J. Membrane Sci. 292: 98-105.

[14] Jouanneau, J., R. Mercier., L. Gonon, and G. Gebel. 2007. Synthesis of Sulfonated Polybenzimidazoles from Functionalized Monomers: Preparation of Ionic Conducting Membranes. Macromolecules. 40: 983-990.

[15] Sone,Y., P. Elkdunge, and D.Simonsson.1996. Proton Conductivity of Nafion 117 as Measured by a Four Electrode AC Impedance Method. J. Electrochem. Soc. 143: $1254-1259$

[16] Ling, J, and O. Savadogo. 2004A. Comparison of methanol crossover among four types of nafion membranes, $J$. Electrochem. Soc. 151:1604-1610.

[17] Ren, X., T. E. Springer, and T. Zawodzinski. 2000. Water and Methanol Uptakes in Nafion Membranes and Membrane Effects on Direct Methanol Cell Performance. J. Electrochem. Soc.147: 92-98.

[18] Wayne, W., Y. Lau, and Y. Jiang. 1994. Performance of polysulfone / carboxylated polysulfone membranes. Polym. Int. 33: 413-417.

[19] Chen, Sheng-Li., A.B. Bocarsly, and J. Benziger.2005. Nafion-layered sulfonated polysulfone fuel cell membranes. J. Power Sources. 152: 27-33.

[20] Heinzel, A, and V.M. Barragan.1999. A review of the state-of-the-art methanol crossover in direct methanol fuel cells. J. Power Sources. 84: 70-74. 